FERnANDA PolisSenN ${ }^{1}$

HOMERO GONÇALVES JÚNIOR ${ }^{1}$

VICENTE RozAURO VIDAL ${ }^{2}$

FLÁVIA LOPES MACEDO ${ }^{3}$

BETINA DINIZ LINS ${ }^{4}$

Juliana Delgado Campos ${ }^{5}$

Nathálla Barbosa Mattos ${ }^{6}$

Relato de Caso

Palavras-chave

Hiperandrogenismo/complicações

Virilismo/etiologia

Hirsutismo

Neoplasias ovarianas/complicações

Hormônios esteroides gonodais

Climatério

Pós-menopausa

Relatos de casos

Keywords

Hyperandrogenism/complications

Virilism/etiology

Hirsutism

Ovarian neoplasms/complications

Gonodal steroid hormones

Climacteric

Postmenopause

Case reports

\title{
Síndrome hiperandrogênica em mulher na pós-menopausa: relato de caso
}

\section{Hyperandrogenic syndrome in a postmenopausal woman: a case report}

\section{Resumo}

As síndromes hiperandrogênicas englobam doenças que se manifestam através de um aumento da atividade biológica dos androgênios e podem ter origem em patologias neoplásicas ou funcionais. Os tumores ovarianos secretores de androgênios constituem cerca de $1 \%$ das neoplasias do ovário. O tumor de células esteroides é um dos tipos mais raros, sendo responsáveis por menos de 0,1\% de todos os tumores ovarianos. São habitualmente benignos, de pequenas dimensões e unilaterais. Neste relato, apresenta-se o caso raro de um tumor unilateral de células esteroides. Paciente do sexo feminino, 60 anos, por hirsutismo, hipertorfia do clitóris e elevação dos níveis séricos de estradiol, com quatro meses de evolução. Apresentava níveis elevados de testosterona total e de 17-OH-Progesterona.

\section{Abstract}

Hyperandrogenic syndromes include diseases that manifest through an increased biological activity of androgens and that can originate from neoplastic or functional diseases. Androgen-secreting ovarian tumors represent about $1 \%$ of ovarian neoplasias. Steroid cell tumors are among the more rare types which account for less than $0.1 \%$ of all ovarian tumors. They are usually benign, of small dimensions and unilateral. We report here a rare case of a unilateral steroid cell tumor. A 60-year-old woman was seen after four months of evolution of hirsutism, clitoris hypertrophy and elevation of serum estradiol levels. Her total testosterone and 17-OH-progesterone levels were also increased.

Correspondência:

Fernanda Polissen Hospital Universitário da Faculdade de Medicino da Universidade Federal de Juiz de For Rua Catulo Breviglieri, $s / n^{\circ}$ Santa Catarina - CEP: 36030-110 Juiz de Fora (MG), Brasi

Recebido 08/04/2011

Aceito com modificaçōes 09/08/2011
1 Professores Adjuntos do Serviço de Ginecologia da Faculdade de Medicina da Universidade Federal de Juiz de Fora - UFJF - Juiz de Fora (MG), Brasil.

2 Professor Titular do Serviço de Ginecologia da Faculdade de Medicina da Universidade Federal de Juiz de Fora - UFJF - Juiz de Fora (MG), Brasil.

${ }_{3}^{3}$ Professora convidada do Serviço de Endocrinologia da Faculdade de Medicina da Universidade Federal de Juiz de Fora - UFJF - Juiz de Fora (MG), Brasil.

${ }^{4}$ Residente do Serviço de Patologia do Hospital Universitário da Universidade Federal de Juiz de Fora - UFJF - Juiz de Fora (MG), Brasil.

${ }^{5}$ Monitora bolsista da disciplina de Ginecologia da Faculdade de Medicina da Universidade Federal de Juiz de Fora - UFJF - Juiz de Fora (MG), Brasil.

${ }^{6}$ Bolsista de treinamento profissional da disciplina de Ginecologia da Faculdade de Medicina da Universidade Federal de Juiz de Fora - UFJF - Juiz de Fora (MG), Brasil.

Conflito de interesses: não há 


\section{Introdução}

As síndromes hiperandrogênicas englobam doenças que se manifestam através de um aumento da atividade biológica dos androgênios ${ }^{1-3}$. Quando acometida, a mulher adulta pode apresentar uma ampla gama de manifestações clínicas, que incluem: hirsutismo, acne, alopécia tipo androgênica, disfunção menstrual, infertilidade, abortamento precoce, síndrome metabólica e sinais de virilização, como atrofia do parênquima mamário, alteração da tonalidade da voz, redistribuição de massa muscular e clitoromegalia ${ }^{1,3-7}$. Dentre estes, o hirsutismo é um dos principais sinais, estando presente em, aproximadamente, $10 \%$ dos casos e é definido como o aparecimento de pelos terminais na mulher, em áreas anatômicas características de distribuição masculina ${ }^{3,5,8}$.

É importante salientar que nem sempre existe correlação entre os níveis de androgênios circulantes e a intensidade das manifestações clínicas?

Uma classificação prática, baseada na clínica, subdivide as síndromes hiperandrogênicas na mulher adulta em dois grupos, segundo a presença ou não de sinais de virilização: síndromes virilizantes e síndromes não virilizantes. As primeiras se caracterizam por uma taxa de produção de testosterona bastante elevada, com uma concentração sérica deste hormônio, normalmente, maior que $200 \mathrm{ng} / \mathrm{dL}$, e pela presença dos sinais de virilização. Ocorrem em decorrência de doenças neoplásicas (tumores adrenais e ovarianos) ou funcionais (hipertecose do ovário ou hiperplasia do estroma cortical). Já as síndromes não virilizantes se caracterizam por níveis séricos de testosterona pouco alterados, com uma concentração normal ou levemente elevada (raramente maior que $200 \mathrm{ng} / \mathrm{dL}$ ). Relacionam-se às patologias funcionais não neoplásicas, como a forma não clássica da deficiência de 21-hidroxilase (hiperplasia adrenal congênita, forma não clássica), o hirsutismo idiopático e a síndrome dos ovários policísticos ${ }^{3}$.

Os tumores secretores de androgênios são raros, estando presentes em cerca de $0,2 \%$ das mulheres que apresentam hiperandrogenemia ${ }^{5}$. Podem ter origem ovariana ou adrenal, sendo a primeira mais frequente ${ }^{4}$.

Entre os tumores ovarianos secretores de androgênio encontram-se os tumores dos cordões sexuais-estroma que são divididos em três subtipos: luteoma do estroma, tumor de células de Leydig e tumor de células esteroides, sem outra especificação ${ }^{4,9-12}$. Os tumores de células esteroides são responsáveis por menos de $0,1 \%$ de todos os tumores ovarianos e podem ser encontrados em qualquer idade, sendo mais comuns após a quarta década de vida. Devem ser sempre suspeitados na vigência de sintomas virilizantes na pós-menopausa ${ }^{6,11,13}$. Os tumores de células esteroides estão associados aos sinais de hiperandrogenismo em frequência variável (12 a 50\% $)^{11}$.

Ao contrário das pacientes com tumores ovarianos epiteliais comuns, dos quais $75 \%$ estão em estágio III ou
IV no momento do diagnóstico, aproximadamente $70 \%$ das pacientes com estes tumores apresentam lesão em estádio I no diagnóstico. Consequentemente, os tumores dos cordões sexuais-estroma são primariamente tratados cirurgicamente e têm, geralmente, bom prognóstico. Como a maioria destes tumores é diagnosticada em estágio inicial e não apresenta recorrência ou metástases, muito pouco se sabe a respeito de sua resposta às medidas terapêuticas complementares, como quimioterapia e radioterapia $^{14,15}$.

O caso relatado se refere a uma paciente na pósmenopausa que desenvolveu quadro agudo de síndrome hiperandrogênica, cuja investigação propedêutica levou ao diagnóstico de um tumor ovariano de células esteroides, sem outra especificação.

Tendo em vista a raridade deste tumor, torna-se importante o relato do caso, destacando-se as etapas diagnósticas e terapêuticas envolvidas.

O estudo foi avaliado e aprovado pelo Comitê de Ética em Pesquisa do Hospital Universitário da Faculdade de Medicina da Universidade Federal de Juiz de Fora.

\section{Relato de caso}

Paciente de 60 anos, do sexo feminino, casada, referenciada ao Ambulatório de Ginecologia do Hospital Universitário da Universidade Federal de Juiz de Fora (HU-UFJF) devido à queixa de hirsutismo e hipertrofia de clitóris e constatação, em exames de rotina na endocrinologia, de níveis séricos de estradiol elevados $(84 \mathrm{pg} / \mathrm{mL}$ ).

A paciente referiu aparecimento de pelos em região mentoniana, dorso, tórax, raiz das coxas, além de hipertrofia de clitóris e aumento da libido, iniciados cerca de quatro meses antes da consulta. O quadro desencadeara um desajuste conjugal, o que a preocupava bastante.

Tinha história pregressa de hipertensão arterial sistêmica e diabetes mellitus tipo II, em tratamento com metformina, glibenclamida e captopril. Apresentou menarca aos 14 anos, ciclos menstruais regulares no menacme e menopausa aos 51 anos, sem uso de terapia de reposição hormonal. Teve quatro gestações, dois abortos, um parto cesáreo e um parto vaginal a fórceps. História familiar de diabete melito tipo II e hipertensão arterial sistêmica (irmãos), pais falecidos, hipertensos e cardiopatas. Duas filhas saudáveis. Referiu etilismo social e negou tabagismo.

Ao exame, apresentava quadro de hirsutismo com presença de pelos terminais nas regiões mencionadas (pontuação 16 na escala de Ferriman-Gallwey) (Figura 1). Massa muscular com distribuição compatível com o sexo. Mamas com parênquima preservado, ausência de galactorreia. Palpação abdominal normal, sem massas ou visceromegalias. Pilificação genital andróide, clitóris hipertrofiado (Figura 2). Exame especular sem alterações. Toque 
bimanual evidenciando útero de volume normal e anexos não palpáveis. Foram solicitados ultrassonografia (USG) transvaginal, USG abdominal e avaliação hormonal.

No retorno, cerca de um mês após a primeira consulta, a paciente referiu aumento da libido, inclusive com interesse homossexual, juntamente com exacerbação do hirsutismo e da hipertrofia do clitóris. Trouxe resultado de exames: 17- $\alpha$-hidroxiprogesterona: $587 \mathrm{ng} / \mathrm{dL}$ (VR 20-172); testosterona total: $1,5 \mathrm{pg} / \mathrm{dL}$ (VR mulher $0,2-1,0$ );

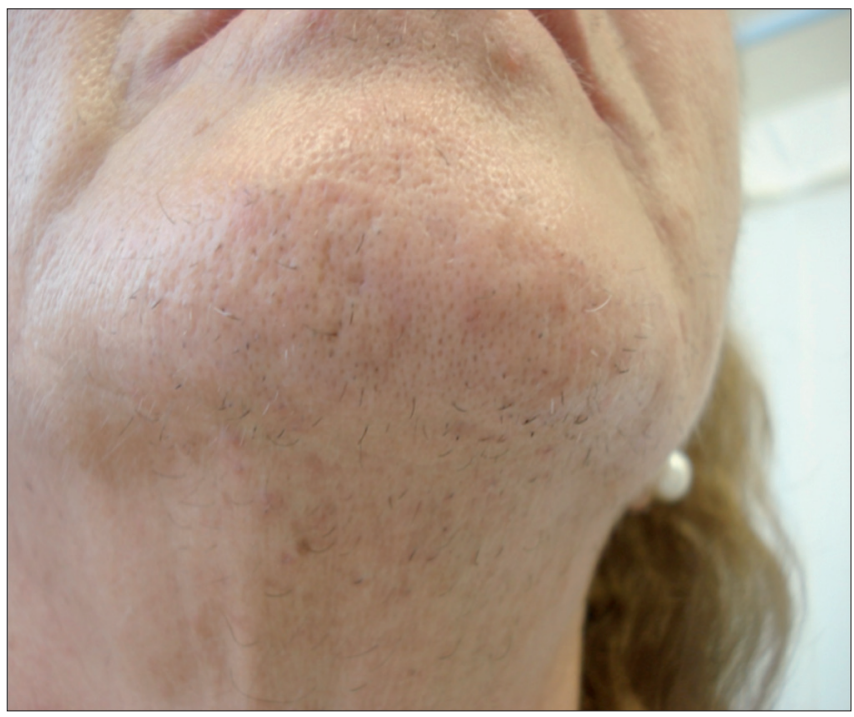

Figura 1. Presença de pelos terminais em região mentoniana, com distribuição tipicamente masculina, em paciente com síndrome hiperandrogênica, representando o hirsutismo.

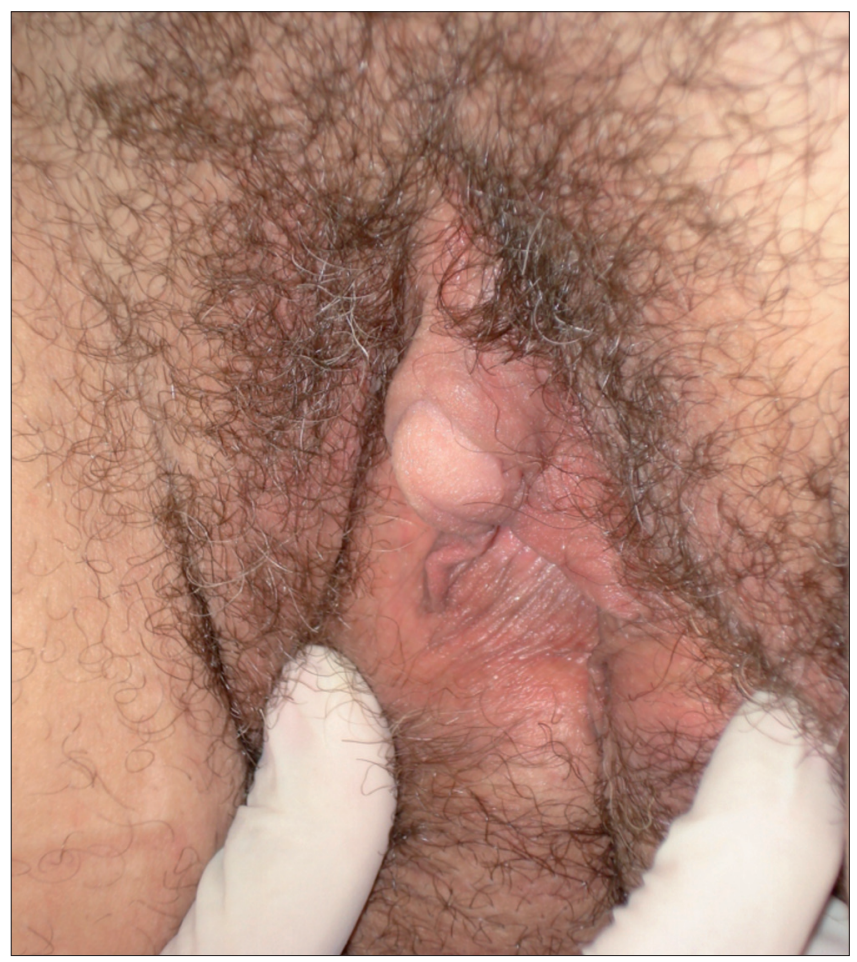

Figura 2. Hipertrofia de clitóris como consequência de hiperandrogenismo. testosterona livre: $2 \mathrm{pg} / \mathrm{dL}$ (VR 0,3-2,5); SDHEA: 80,4 mcg/dL (VR 35-430); USG transvaginal: útero de volume normal, endométrio com $6,7 \mathrm{~mm}$ de espessura e ovários sem alterações.

Como os primeiros exames mostraram-se inconclusivos e diante da possibilidade de doença suprarrenal ou ovariana, novos exames foram solicitados: Tomografia computadorizada (TC) abdomino-pélvica, repetição das dosagens hormonais e investigação endometrial, em decorrência do espessamento constatado à USG transvaginal.

$\mathrm{Na}$ consulta subsequente, a paciente permaneceu com queixas de virilização e relatou sangramento genital, com duração de 1 dia, ocorrido 20 dias antes desta consulta. Resultado de exames: 17- $\alpha$-hidroxiprogesterona: $547 \mathrm{ng} / \mathrm{mL}$, novo USG transvaginal, realizado após sangramento genital, mostrando ovários de formato e ecotextura normais, medindo o direito $2,1 \times 3,5 \mathrm{~cm}$ e o esquerdo $1,9 \times 3,1 \mathrm{~cm}$ e endométrio com espessura de $5,5 \mathrm{~mm}$, o que dispensou a investigação endometrial complementar. Na TC abdomino-pélvica, evidenciou-se ovário esquerdo com volume aumentado $\left(4,3 \mathrm{~cm}^{3}\right)$, apresentando realce heterogêneo. Adrenais dentro dos padrões de normalidade. Não havia ascite, linfoadenopatia retroperitoneal ou metástases hepáticas (Figura 3). A partir deste laudo, a propedêutica foi direcionada para uma possível origem ovariana, com ressonância magnética (RNM) pélvica evidenciando lesão ovalada em região anexial esquerda com hipossinal em T1 e leve hipersinal em T2, medindo 3,9 × 3,4 × 3,4 cm, apresentando realce intenso e precoce pelo meio de contraste.

Foi indicado tratamento cirúrgico para remoção da massa anexial. Antes do tratamento cirúrgico, enquanto aguardava a avaliação pré-operatória, a paciente,

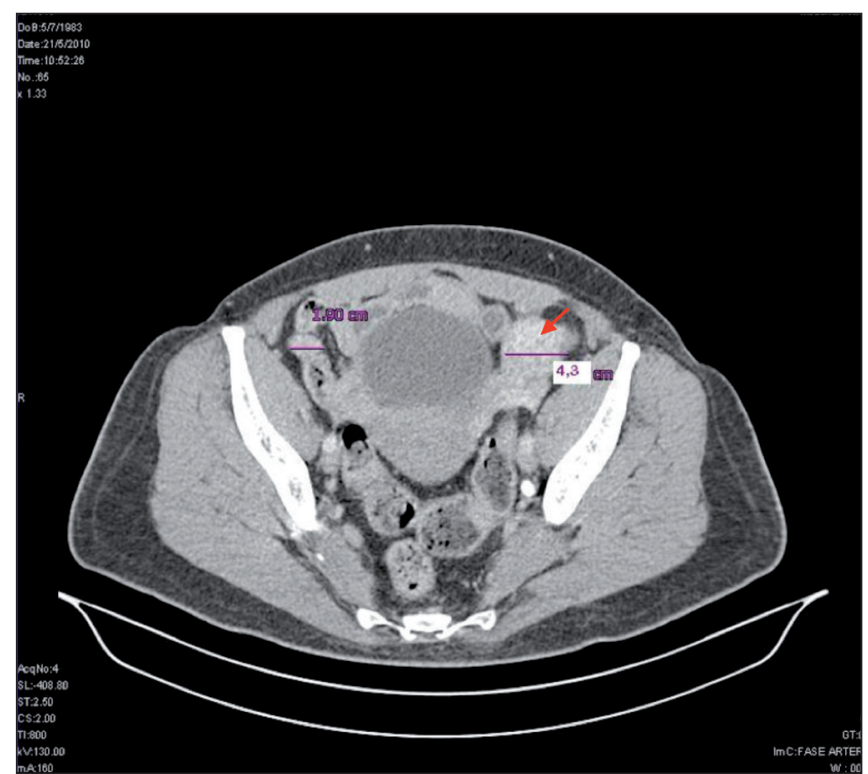

Figura 3. Tomografia computadorizada de abdome e pelve evidenciando ovário esquerdo (seta) com volume aumentado $\left(4,3 \mathrm{~cm}^{3}\right)$ e realce heterogêneo. 
extremamente incomodada com os sintomas, foi medicada com acetato de ciproterona $100 \mathrm{mg}$ ao dia, durante 40 dias. Houve melhora parcial dos sinais de virilização e adequação parcial da libido.

O tratamento cirúrgico instituído foi a histerectomia total com anexectomia bilateral por laparotomia abdominal. Não se registraram quaisquer intercorrências pré ou perioperatórias. No ato operatório, observou-se um ovário esquerdo de volume aumentado, contornos tridimensionais irregulares e consistência fibrosa. Ovário direito, trompas e útero sem alterações. Não foi observada qualquer outra alteração na inspeção da cavidade pélvica e abdominal.

Na macroscopia, o exame anatomopatológico evidenciou: útero, cavidade uterina, tubas e ovário direito com aspecto habitual. Ovário esquerdo media $3,5 \times 3,0 \times 2,7 \mathrm{~cm}$, encapsulado, bocelado, de coloração parda amarelada. Aos cortes, observou-se superfície sólida, amarelo ouro, com delicada trama delimitando nodulações de dimensões variadas. Na microscopia, o ovário esquerdo apresentava substituição em torno de $90 \%$ do parênquima habitual por proliferação neoplásica, de aspecto vagamente nodular, constituída por dois padrões celulares. Um padrão exibiu células poligonais de tamanho médio a grande com citoplasma finamente granular, eosinofílico, núcleos centrais e nucléolos proeminentes. O segundo padrão celular era constituído por células grandes, citoplasma abundante e vacuolado. Pigmento lipocrômico intracitoplasmático foi ocasionalmente observado. Havia atipia nuclear discreta, sem evidência significativa de atividade mitótica. Um componente fibromatoso delicado foi evidenciado delimitando nódulos (Figura 4). Tendo em vista tratar-se de um tumor de células esteroides, sem outra especificação, foi solicitado estudo imuno-histoquímico para melhor caracterização do processo.

Neste estudo, realizado pelo Laboratório Cito, foram pesquisados os marcadores relacionados a seguir juntamente com os resultados obtidos (Figura 5): anti-buman melan A (clone A103 1:100 TE, MW): positivo difuso com fraca intensidade; coquetel de citoqueratinas (clone AE1/AE3, 1:500, TE, MW, Signet): negativo; antígeno de membrana epitelial [EMA] (clone E29, 1:200,TE,MW): negativo; anti-calretinin (clone 5 A 5 , 1:100, TE, MW, Novocastra):positividade intensa e difusa, citoplasmática e nuclear; anti-alfa inhibin (clone R1,1:50, TE, MW): positividade citoplasmática difusa e vimentina (clone V9, 1:2000, TE, MW): positividade difusa.

Os achados imuno-histoquímicos foram, então, consistentes com tumor de células esteroides, sem outra especificação.

Com um mês de pós-operatório, a paciente foi reavaliada tendo sido evidenciada considerável diminuição da libido e do clitóris, e melhora discreta do hirsutismo. $\mathrm{Na}$ ocasião, a paciente queixou-se de fogachos. Foram

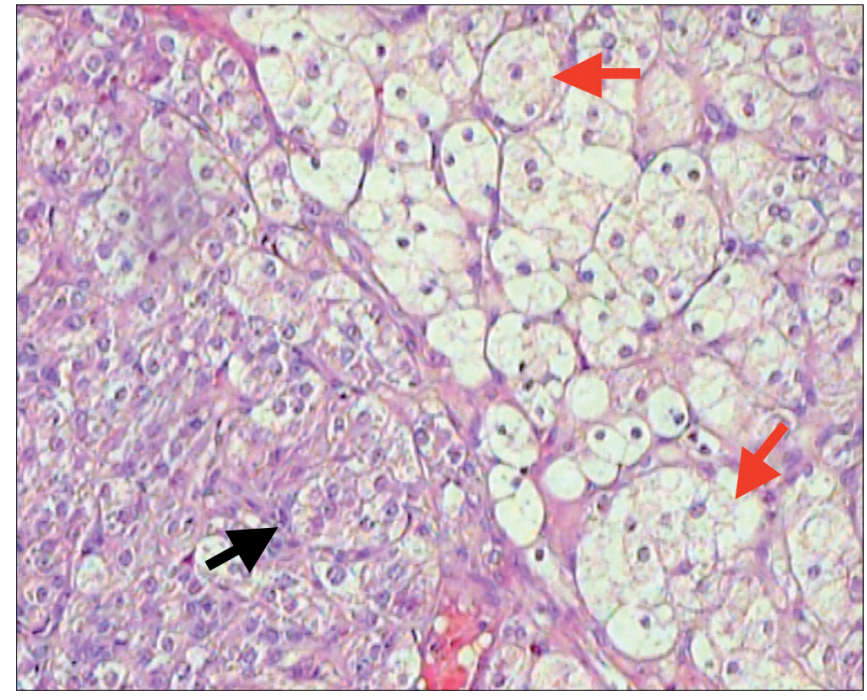

Figura 4. Tumor de células esteroides. Dois padrões celulares: células com citoplasma abundante, eosinofílico (seta preta); células com citoplasma claro, vacuolado (seta vermelha) (400x).

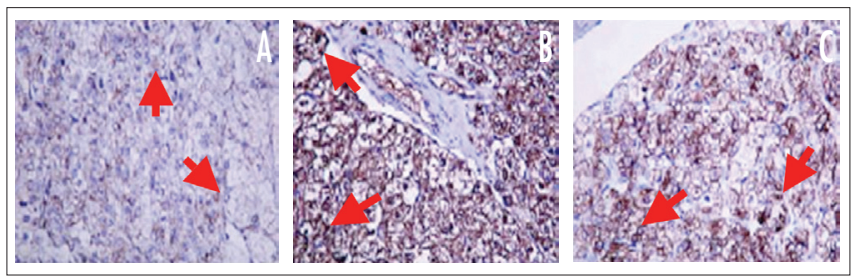

Figura 5. Imuno-histoquímica. (A) Melan A: marcação difusamente positiva com fraca intensidade - setas (100x). (B) Calretinina; positividade intensa e difusa, nuclear e citoplasmática - setas (200x). (C) Inibina; marcação citoplasmática fortemente positiva e difusa - setas (200x).

solicitadas dosagens de androgênios, e orientado acompanhamento trimestral, no primeiro ano. Prescrito estradiol hemiidratado $0,1 \%$ em gel, em ultrabaixa dose $(0,5 \mathrm{mg}$ de estradiol/dia), via transdérmica, para alívio dos sintomas vasomotores. Os resultados dos exames demonstraram normalização dos níveis de androgênios.

\section{Discussão}

As síndromes hiperandrogênicas englobam doenças que se manifestam através de um aumento da atividade biológica dos andrógenos. Sinais de virilização estão presentes quando há aumento acentuado na taxa de produção de testosterona que, em geral, mas não obrigatoriamente, é acompanhada de elevação correspondente nas concentrações séricas do hormônio ${ }^{3}$.

Embora os exames laboratoriais possam confirmar o diagnóstico de uma síndrome hiperandrogênica virilizante, este é, eminentemente, clínico. No caso relatado, a paciente apresentava sinais clássicos de virilização, inclusive com queixa de inadequação psicossocial, em função da alteração da libido, sua principal queixa. 
A abordagem destas síndromes deve ser cuidadosa visto que, além da repercussão orgânica, há o impacto psicossocial. Hirsutismo, clitoromegalia, alteração na tonalidade da voz, alteração da libido, aumento da massa muscular, entre outros, podem provocar alterações na vida social e conjugal da paciente ${ }^{16}$.

A conduta imediata, perante um quadro de hiperandrogenismo com virilização, deve ser a pesquisa da etiologia específica, objetivando-se suprimir a secreção anormal de androgênios. Como os ovários são responsáveis pela produção direta de um terço da testosterona total e participam direta e indiretamente na formação dos dois terços restantes, a dosagem de testosterona pode ser considerada um marcador biológico da contribuição androgênica ovariana. Do mesmo modo, a deidroepiandrosterona é produzida quase que exclusivamente pela suprarrenal, tendo a sua forma sulfatada uma importância clínica específica como marcador biológico da contribuição androgênica dessa glândula, sobretudo, quando encontra-se em nível superior a $800 \mathrm{mcg} / \mathrm{dL}$. Dessa forma, a dosagem desses marcadores biológicos tem grande importância no diagnóstico diferencial da glândula produtora do hiperandrogenismo ${ }^{9,10,15}$. Níveis séricos elevados de $\mathrm{Ca} 125$ podem direcionar o diagnóstico para uma origem ovariana do tumor ${ }^{14}$.

O estudo morfológico dos ovários e das adrenais, com uso da USG ou, eventualmente, da tomografia computadorizada ou da ressonância magnética, também são importantes para o diagnóstico diferencial destas neoplasias. Todavia, os exames de imagem podem falhar na localização de tumores pequenos, como observado neste relato $^{1,5,8,9,17,18}$. Neste caso, a paciente havia apresentado duas USG transvaginais normais. Apenas a TC abdominopélvica e, posteriormente, a RNM de pelve foram capazes de identificar a lesão ovariana. As características da TC e da RNM, nos tumores de células esteroides, variam de acordo com a quantidade de componente lipídico celular e de estroma fibroso. O tumor pode apresentar intenso realce à RNM, significando hipervascularização ${ }^{19-24}$. Apesar de níveis séricos elevados de 17-OH-progesterona encontrados nesta paciente, a TC abdomino-pélvica não evidenciou quaisquer alterações na suprarrenal, o que suporta a exclusão de patologias desta glândula. O diagnóstico definitivo é dado pelo estudo anatomopatológico que, muitas vezes, precisa ser confirmado pela análise imuno-histoquímica do material ${ }^{11}$.

Os tumores de células esteroides correspondem a menos de $0,1 \%$ de todos os tumores ovarianos. Em revisão da literatura realizada entre os anos de 1979 e 2007, Kim et al. ${ }^{18}$ encontraram apenas 74 casos de tumor de células esteroides relatados. Hayes e Scully ${ }^{23}$ relataram 63 casos de pacientes com tumor de células esteroides, com idade entre 2 e 80 anos. O subtipo tumor de células esteroides sem outra especificação estava associado às manifestações de hiperandrogenismo em $50 \%$ das pacientes. Dos tumores encontrados, 94,0\% eram unilaterais e $28,6 \%$ eram malignos ${ }^{18,23}$. Estes tumores fazem parte do grupo de tumores dos cordões sexuais-estroma e usualmente são benignos, unilaterais e caracterizados por uma proliferação de células esteroides. Os tumores dos cordões sexuais-estroma estão divididos em três subtipos: luteoma, tumor de células de Leydig e tumor de células esteroides, sem outra especificação, sendo o último o mais comum dos três subtipos, correspondendo a $60 \%$ dos $\operatorname{casos}^{15}$. O subtipo Não Especificado é dividido, de acordo com as características do citoplasma celular, em vacuolizado ou eosinofílico ${ }^{12,16}$.

Os tumores de células esteroides, usualmente, apresentam muitos anos de evolução ${ }^{16}$. O caso aqui relatado é único, por seu desenvolvimento agudo, com instalação abrupta dos sinais de virilização. Além disto, não são comuns as manifestações estrogênicas associadas a este tipo de tumor ${ }^{18}$, o que confirma a relevância do relato. $\mathrm{O}$ aumento do estradiol é detectado em 6-23\% das pacientes e nestes casos, menorragia e sangramentos irregulares na pós-menopausa podem estar presentes ${ }^{16}$. Neste caso, a paciente foi referenciada ao serviço de Ginecologia por apresentar, em avaliação periódica na Endocrinologia, níveis séricos elevados de estradiol. Apresentou, ainda, estimulação endometrial com detecção de espessamento a USG transvaginal. Posteriormente, apresentou quadro de sangramento genital. A estimulação endometrial observada pode ser explicada pela conversão periférica de androgênios em estrogênios, via aromatase, ou pela produção de estrogênios pelo próprio tumor ${ }^{3,10,11,14,23}$. Aproximadamente $25 \%$ dos tumores de células esteroides, sem outra especificação, não produzem hormônios ${ }^{14}$.

A maioria dos tumores de células esteroides tem um comportamento benigno, mas, aproximadamente, 20\% das pacientes desenvolvem lesões metastáticas, usualmente para o interior da cavidade peritoneal e, raramente, à distância. Estes tumores são tipicamente sólidos, bem circunscritos e, ocasionalmente, lobulados, apresentando um diâmetro médio de $8,4 \mathrm{~cm}^{14}$.

Hayes e Scully ${ }^{23}$ identificaram cinco padrões anatomopatológicos altamente associados à malignidade, nos tumores de células esteroides: mais de duas mitoses por campo de maior aumento, necrose, tamanho tumoral igual ou maior que $7 \mathrm{~cm}$, hemorragia, grau dois ou três de atipia nuclear ${ }^{18,20-22}$. No caso relatado, o exame anatomopatológico do tumor não identificou padrões associados à malignidade.

O diagnóstico patológico final é baseado nas características histológicas, incluindo células poligonais e redondas grandes, com citoplasma abundante. Algumas células podem apresentar um citoplasma claro, vacuolado, 
lembrando as células do córtex adrenal. Outras têm citoplasma denso, eosinofílico, lembrando células de Leydig, exceto pela ausência de cristais de Reinke. Os dois tipos celulares podem estar presentes, mais um dos dois pode predominar ${ }^{19}$.

A imuno-histoquímica tem se tornado uma importante ferramenta no diagnóstico diferencial de tumores ovarianos derivados do cordão sexual de outros tumores ovarianos primários, sobretudo, dos adenocarcinomas endometrióides ${ }^{16}$. Nesse contexto, a inibina tem sido usada como o principal marcador para tumores originados do estroma gonadal especializado, raramente sendo positiva para adenocarcinomas endometrióides. Contudo, pode ser positiva em outros tumores ovarianos, devendo ser analisada junto a outros marcadores tumorais, incluindo calretinina e melan A humana. A calretinina é mais sensível do que a inibina, porém, menos específica, podendo ser positiva nos tumores epiteliais. O melan A humana é um marcador de tumores dos cordões sexuais-estromal e de tumores produtores de esteroides, inclusive fora do ovário ${ }^{13,16,18,24}$.

No nosso caso, o estudo anatomopatológico evidenciou características compatíveis com tumores de células esteroides, o que foi corroborado pelo perfil imuno-histoquímico. Houve positividade para inibina, calretinina e vimentina, o que classificou o tumor como originário do cordão sexual $^{17-19}$. Já a positividade verificada para melan A caracteriza o tumor como de células esteroides.

O manejo das pacientes portadoras de um tumor de células esteroides deve ser individualizado, baseado nos resultados do estudo anatomopatológico, estadiamento cirúrgico e no desejo de preservar a fertilidade ${ }^{16}$. A princípio, o tratamento é a cirurgia, sendo, habitualmente, realizada a histerectomia total abdominal, salpingooforectomia bilateral, e o estadiamento cirúrgico, principalmente quando se trata de mulheres que não pretendem ter mais filhos ou que estejam na pós-menopausa, como neste caso. Por outro lado, em pacientes jovens faz-se, frequentemente, salpingooforectomia unilateral, prática que requer acompanhamento rigoroso, com dosagens hormonais e exames de imagem periódicos para detectar uma possível recidiva ${ }^{14-16}$.

Sabe-se que os tumores de células esteroides histologicamente benignos podem ter um comportamento clínico maligno. Desta forma, um acompanhamento cuidadoso é essencial, mesmo nos casos em que não há evidência clínica ou histopatológica de malignidade. Algumas vezes, a presença de metástases pode ser a única evidência de comportamento maligno ${ }^{13}$.

A terapêutica cirúrgica por si só é suficiente na maioria das pacientes, com exceção daquelas que apresentem doença disseminada ou que, mesmo não apresentando metástases, apresentem um tumor pouco diferenciado ou com elementos heterólogos. Aos sinais de malignidade, é ainda discutível a realização de quimioterapia e radioterapia adjuvante, pois como a maioria dos tumores é diagnosticada em fases iniciais, não recidivam, nem apresentam metástases, a avaliação das terapias adjuvantes no tratamento torna-se difícil ${ }^{11,12,16}$. Quimioterapia combinada, à base de platina, parece ser a mais indicada para estes $\operatorname{casos}^{16}$.

O seguimento destas doentes é realizado com exame físico e avaliação dos níveis de testosterona a cada três a quatro meses nos primeiros dois anos, e de seis em seis meses nos três anos subsequentes ${ }^{4}$. Este caso é único por sua apresentação aguda, em um período de poucos meses. O presente caso confirma que os tumores secretores de androgênio representam um desafio diagnóstico e terapêutico e devem ser considerados no diagnóstico diferencial das síndromes hiperandrogênicas da mulher na pós-menopausa.

\section{Agradecimentos}

Ao Serviço de Patologia do Hospital Universitário da Universidade Federal de Juiz de Fora, em especial à Profa. Ângela Gollnere ao Laboratório Cito pelas análises anatomopatológica e imuno-histoquímica do presente caso.

\section{Referências}

1. Villarreal-Tordecilla GA. Estados hiperandrogénicos: revisión de la literatura. Rev Colomb Obstet Ginecol. 2009;60(4):357-64.

2. Yarak S, Bagatin E, Hassun KM, Parada MOAB, Talarico Filho $S$. Hiperandrogenismo e pele: síndrome do ovário policístico e resistência periférica à insulina.An Bras Dermatol. 2005;80(4):395-410.

3. Marcondes JAM. Hirsutismo: diagnóstico diferencial. Arq Bras Endocrinol Metab. 2006;50(6):1 108-16.
4. Marcelino M, Nobre E, Conceição J, Lopes L, Vilar H, França M, et al. Um caso raro de hiperandrogenismo - Tumor ovárico bilateral de células de Leydig. Acta Med Port. 2010;23(1):113-8.

5. Spritzer PM. Diagnóstico etiológico do hirsutismo e implicações para o tratamento. Rev Bras Ginecol Obstet.2009;31 (1):41-7.

6. Vexiau P, Chaspoux C, Boudou P, Fiet J, Abramovici Y, Rueda M, et al. Role of androgens in female-pattern androgenetic alopecia, 
either alone or associated with other symptoms of hyperandrogenism. Arch Dermatol Res. 2000;292(12):598-604.

7. Cheviakoff Z S, Carmona G S, Lahsen M de la P R. Estúdio de variables clínicas y metabólicas em mujeres con hiperandrogenismo clínico. Rev Chil Obstet Ginecol. 2004;69(1):39-43.

8. Sociedade Brasileira de Endocrinologia e Metabologia, Sociedade Brasileira de Dermatologia. Hirsutismo: diagnóstico. Rev Assoc Med Bras. 2010;56(1):6-8.

9. Pinheiro SA, Clapauch R. Importância da dosagem da $170 \mathrm{H}$ progesterona na síndrome dos ovários policísticos. Arq Bras Endocrinol Metab. 2001;45(4):361-8.

10. Taboada GF, Teixeira RJ, Corrêa FHS, Andrade Júnior CRM, Dimetz T, Hohleuwerger R. Sensibilidade, especificidade e valor preditivo dos níveis basais da 17-hidroxiprogesterona no diagnóstico da forma não-clássica da hiperplasia adrenal congênita por deficiência da 21-hidroxilase. Arq Bras Endocrinol Metab. 2003;47(5):552-7.

1 1. Young RH, Shully RE. Steroid cell tumors of the ovary. In: Fox H,Wells $M$, editors. Obstetrical \& gynecological pathology. Edinburgh: Churchill Livingstone; 2003. p. 845-56.

12. Nardo LG, Ray DW, Laing I, Williams C, McVey RJ, Seif MW. Ovarian Leydig cell tumor in a peri-menopausal woman with severe hyperandrogenism and virilization. Gynecol Endocrinol.2005;21(4):238-41.

13. Mehdi G, Ansari HA, Sherwani RK, Rahman K, Akhtar N. Ovarian steroid cell tumour: correlation of histopathology with clinicopathologic features. Pathol Res Int. 2011 1;2011:987895.

14. Mastrolia SA,Alvarez-Arguelles H, Carballo J, Amaya F, Torre J. Steroid cell tumor (NOS) of the ovary associated to high levels of CA-125. Gynecol Surg. $2011 ; 8(2): 231-3$.

15. Haji AG, Sharma S, Badu M, Vijaykumar DK, Chitrathara K. Androgen secreting steroid cell tumor of the ovary in a young lactating women with acute onset of severe hyperandrogenism: a case report and review of literature. J Med Case Reports. 2007; $1: 182$

16. Tsukasa S, Yumiko T, Manabu M. Steroid cell tumor of ovary, not otherwise specified: CT and MR findings. AJR Am J Roentgenol. 2007; 188(4):393-4.

17. Fuertes LV, Calle MA, Cisneros $G$. Epidemiología y patología de los tumores ováricos. Hospital Carlos Andrade Manarín, años 19962000. CAMBIOS Org Of Difus Cient HCAM. 2003;2(4):240-50.

18. Kim YT, Kim SW, Yoon BS, Kim SH, Kim JH, Kim JW, et al. An ovarian steroid cell tumor causing virilization and massive ascites. Yonsei Med J.2007;48(1):142-6.

19. Deavers MT, Oliva E, Nucci MR. Sex cord-stromal tumors of the ovary. In:Nucci MR, Oliva E, editors. Gynecologic pathology. Boston:Churchill Livingstone; 2009. p. 445-500. (Foundations in diagnostic pathology).

20. Reedy MB, Richards WE, Ueland F, Uy K, Lee EY, Bryant C, et al. Ovarian steroid cell tumors, not otherwise specified: a case report and literature review. Gynecol Oncol. 1999;75(2):293-7.

21. Jung SE, Rha SE, Lee JM, Park SY, Oh SN, Cho KS, et al. CT and MRI findings of sex cord-stromal tumor of the ovary. AJR Am J Roentgenol. 2005; 185(1):207-15.

22. Fernandes LRA, Lippi UG, Baracat FF. Índice de risco de malignidade para tumores do ovário incorporando idade, ultra-sonografia e o CA-125. Rev Bras Ginecol Obstet. 2003;25(5):345-51.

23. Hayes MC, Scully RE. Ovarian steroide cell tumors (not otherwise specified). A clinicopathological analyses of 63 cases. Am J Surg Pathol. 1987; 11(11):835-45.

24. Varras M, Vasilakaki T, Skafida E, Akrivis C. Clinical, ultrasonographic, computed tomography and histopathological manifestations of ovarian steroid cell tumour, not otherwise specified: our experience of a rare case with female virilisation and review of the literature. Gynecol Endocrinol. $2011 ; 27(6): 412-8$. 